Tadeusz Zaborowski

Wyższa Szkoła Logistyki w Poznaniu

E-mail: tadeusz.zaborowski@wsl.com.pl

Leonid Shvartsburg

Moscow State University of Technology "STANKIN"

E-mail: lesh@stankin.ru

Natalia Ivanova

Moscow State University of Technology "STANKIN"

E-mail: ivanova_na2006@mail.ru

Sergej Ryabov

Moscow State University of Technology "STANKIN"

E-mail: zarrr05@mail.ru

Piotr Bernat

Państwowa Wyższa Szkoła Zawodowa w Nysie

E-mail: piotr.bernat@pwsz.nysa.pl

\title{
ECOENERGETIKS CUTTING TECHNIQUES
}

\begin{abstract}
Background: The chapter discusses the relationship between energy quality technologies cutting and their environmental friendliness. Based on the energy analysis shows that energy consumption in the individual technological process is connected with the cutting power and power loss, which form the environmental indicators of the cutting process and reduce its energy efficiency. In addition it is shown that at implementation of technological processes on the equipment, electrical systems are AC systems the implementation of the cutting process occurs when excessive consumption of currents.

Results: The chapter presents the results of studies on the energy efficiency of cutting processes, definition of the complex influence of cutting processes on the environment and humans, the formation of ways of improving environmental and energy performance quality of these processes.
\end{abstract}

Keywords: technology, machining, quality, energy, ecology, interaction, safety 


\section{INTRODUCTION}

The problem of energy consumption reducing and the associated problem of the reducing of impact on environment and human (the environmental friendliness increasing) of shaping processes is relevant for the engineering industries. It results from the fact that the shaping technological processes are one of the most common processes of modern engineering. Products shaping with given quality is the technological environment objective function, including cutting technological processes, equipment for their implementation, automation and control facilities, auxiliary equipment and other means for the objective function implementation. At the same time, at all the stages of its life cycle, the technological environment has a qualitative and quantitative impact on the environment and human (fig. 1) through consumption and waste. This impact is always negative and determines the cutting technologies environmental friendliness and, to a large extent, it determines the competitiveness of both technological environment and the products themselves.

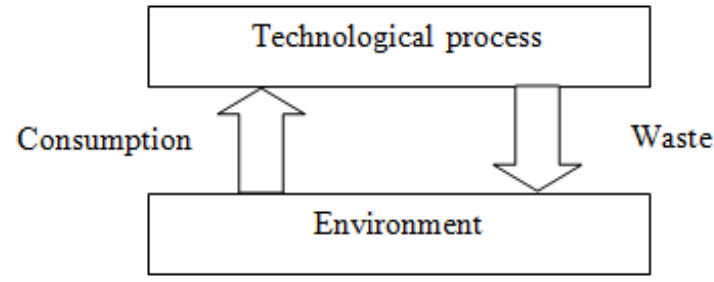

Fig. 1. The impact of technological processes on the environment and human. Source: own work.

For this reason, the priority is being given to solving the energy consumption reducing and environmental friendliness improving problem. This refers to modern approaches to the production organization, to the introduction of modern shaping technologies and information technologies, to other innovations (automation facilities advancement, tool quality improvement, etc.) [Kapitanov, 2016; Shvartsburg et al. 2017; Egorov, Kapitanow and Loktev 2016; Shvartsburg, Butrimowa and Yagolnister 2017; Ivanowa, Ryavbov and Shvartsburg 2016; Yu, Golubkov and Ermoleava 2016; Egorov et al. 2016; Shvartsburg et al. 2014; Rodriguez, Shwartsburg and Artemeyeva 2017].

\section{ECOENERGETIKS CUTTING TECHNIQUES}

The problem of energy consumption reducing and the cutting processes impact on the environment and human is being actively pursued both in Russia and abroad. The studies on this issue and their results have significantly increased cutting processes energy efficiency and environmental friendliness. 
The problem of energy consumption reducing is a major environmental problem, as energy production is a kind of economic activity causing one of the most significant environmental damage.

As for the environmental friendliness, its increasing problem is solved by a limited number of factors (for example, by noise or by some other factor). In this case, either the technological process is improved, or the technological equipment quality is advanced, or certain protective devices are applied. All these are classified among the passive methods of environmental friendliness provision by one of the factors characterizing it.

To disseminate this factor included in the environmental friendliness indicator for the specific type of cutting process a probability measure is used - "ecological risk", determined by the product of the negative event occurrence probability, its impact on the object and the object's negative reaction to this effect, that means it is estimated by probabilistic characteristics. These characteristics do not characterize the actual shaping process effectively enough, as they do not take into account its implementation specific conditions and parameters.

The processes ecological friendliness is a multifactor index. For this reason, in a number of cases the environmental friendliness is assessed according to the statistical characteristics - "environmental indicators" of the same actual cutting process assessment inefficiency as environmental risks. In addition, the shaping processes environmental friendliness and energy efficiency are not evaluated in their interrelationship, complicating the possibility of these indicators management for their improvement.

Despite the great cutting technologies variety, in general cutting process may be represented by two processes - the process of the consumed electrical energy conversion into mechanical energy and the process of the converted energy transfer to the cutting zone [Shvartsburg, Butrimova and Yagolnister 2017a].

For example, the cutting technological process is characterized by a large variety of technological processes types (turning, milling, drilling, etc.) and parameters (cutting speed, feed rate, cutting depth, etc.), equipment types (turning, milling, drilling and other machines), automation level (manual, automated, etc.) However, despite this diversity, all the cutting processes may be represented as the process of electrical energy conversion into mechanical energy through an electromotor and process of mechanical energy transfer into the cutting zone through machine kinematics fig.2. 


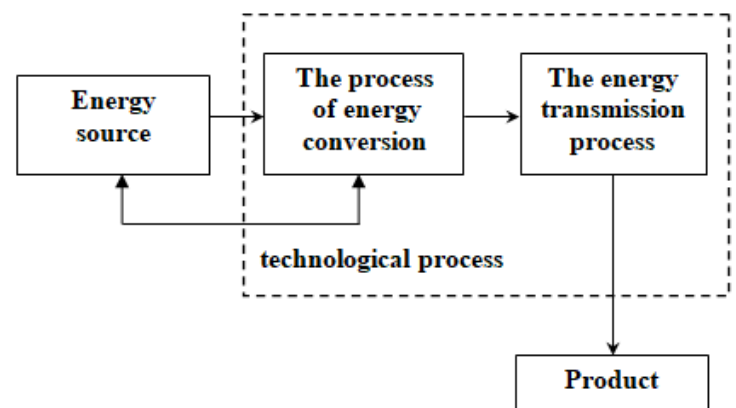

Fig. 2. Shaping technological process energetic representation. Source: own work.

Like any physical processes, the energy conversion and transmission processes are carried out with losses characterized by power losses in the systems performing these processes at energy conversion and its transferring to the processing zone. Let us consider these processes in more detail (fig. 3).

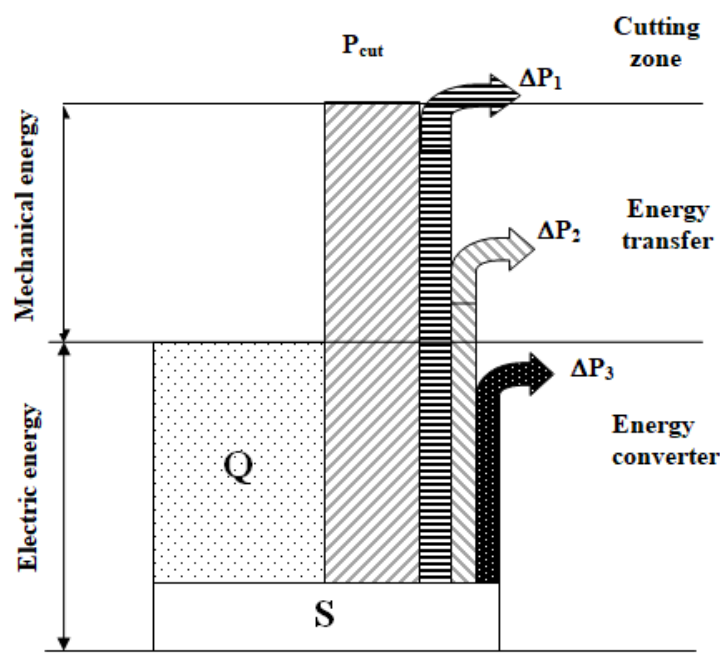

Fig. 3. The technological process energy diagram. Source: own work.

For the technological process implementation, some cutting power $\mathrm{P}_{\text {cut }}$ must be fed to the cutting zone, calculated by the technologist through cutting forces, cutting modes, tool and workpiece parameters. There are also power losses $\Delta \mathrm{P}_{1}$ in the cutting zone, primarily caused by friction and forming thermal waste, resulting in both workpiece and tool thermal deformation and working zone air pollution with the products of thermal destruction of liquid lubricating-cooling components and suspended impurities.

The mechanical energy transfer to the cutting zone is carried out through the machine kinematics, and this transfer also causes energy losses $\Delta \mathrm{P}_{2}$. These losses form both thermal 
pollution, vibration and noise, oil contamination with suspended impurities formed due to wear of equipment kinematic chain moving elements.

Despite the tendency to reduce the machine kinematic chains length and its functions transfer to control systems [Shartsburg, Zaborowski and Cyplik 2017], the importance of these chains in energy analysis remains significant. It is explained by the presence of considerable friction in the machine moving elements and these elements elasticity.

Electrical energy conversion into mechanical energy through the equipment electric motor is also accompanied by energy losses determined by the value of $\Delta \mathrm{P}_{3}$, being primarily the source of electromagnetic and thermal waste.

In the equipment electrical drives alternating current electric motors are often used as a power converter for the cutting processes implementation. Their operation characteristic feature is the presence of a power substantially on the shaft less than this engine rated power. In this case the motor operates at low power factors $\cos \varphi$, that means at the exaggerated consumed currents, determining the high value of reactive component $\mathrm{Q}$ of consumed power (fig. 3), and hence the power consumption $S$ :

$$
s=\frac{P_{\text {cut }}+\sum_{i=1}^{d} \Delta P_{i}}{\cos \varphi}
$$

The low value of $\cos \varphi$ at the shaping technological processes implementation determines the low energy efficiency, which is the most important factor determineing the technological processes low ecological friendliness.

The last expression determines the cutting technologies energy efficiency. Energy efficiency improvement is critical in terms of these technologies environmental impact reduction, as high technological processes energy efficiency leads to electric power sources inefficient use and to significant energy losses.

It should be mentioned that from the physical point of view the technological processes energy intensity reduction means their implementation with lower current consumption, significantly facilitating the power circuits operation and reducing the power consumption active component loss amount.

Thus, the cutting processes environmental friendliness and their energy efficiency are interrelated, allowing to unify the cutting processes ecological friendliness management through their energy efficiency under the term of "ECOENERGETICS".

Technological cutting processes ecological friendliness and energy efficiency increase should be carried out in two directions. 
The first direction is the energy losses reduction at its conversion and transfer to the cutting zone, that means providing:

$$
\Delta P_{i} \rightarrow \min
$$

This direction implementation algorithm is as follows.

Experimentally and/or theoretically, qualitative and quantitative interrelations between the technological processes safety indices, determined by the energy losses $\Delta \mathrm{Pi}$ and these processes parameters (feed rate, cutting depth, etc.) are established. The environmental quality indicators are brought to the required values through the technological processes parameters management on the basis of established relationships.

This algorithm may be implemented in both automatic and non-automatic modes. Its effectiveness was experimentally verified through controlling hexane and phenol concentration in the working zone at turning and at flat grinding, carbon monoxide at electrochemical marking at electromagnetic waste management, vibration and noise at turning and milling. All these allowed to increase the cutting technologies ecological friendliness and energy efficiency by (10-15\%) due to the reduction of energy losses $\Delta \mathrm{Pi}$ at its transformation and transfer to the cutting zone [Gvozdkova and Shvartsburg 2017].

At this algorithm implementation, one should keep in mind the following.

When managing the technological processes parameters on the basis of established relationships, it is possible to change the other quality indicators of these processes. Therefore, it is necessary to solve the optimization, usually multicriteria, problem, on the basis of technological environment mathematical models analysis.

At this algorithm implementation by automated means it is advisable to make maximum use of the existing control system installed on the equipment and managing the parameters traditional for this equipment in order to simplify the control system. For example, for metalcutting turning machines such a system is an adjustable subordinate control system, and the controlled parameters include current $I$ consumed by the motor and the machine moving elements movement speed $\Omega$. In this regard it is necessary first to establish the qualitative and quantitative dependence of the environmental indicator on one of the controlled parameters and to use the control system available at the machine only by supplementing it with the necessary interfaces at the environmental quality indicators provision automating for the machines of this group. It simplifies the automation system considerably, as there is no need to build an additional control system.

It should be mentioned that minimization of losses $\Delta \mathrm{Pi}$ is of great importance for the working conditions improvement, increasing its safety and comfort. 
However, from the point of view of cutting technologies energy efficiency increasing, the power factor increasing is of much greater importance, being the second direction of cutting technological processes ecological friendliness and energy efficiency increasing.

The power factor low value is explained by the cutting technologies implementation specificity - their implementation is carried out at the machines "underload", that means in the conditions where the cutting power applied to the motor shaft is substantially lower than its rated power. The electric motor operation at capacities significantly lower than their rated power is characteristic for any cutting technological process, regardless of the number of technological transitions, cutting modes, type and kind of equipment. This circumstance is further aggravated with obligatory presence in the processing cycle of the product of idle moves, necessary for the tool supply and retraction, its replacement, etc.

From the point of view of energy consumption, the main element of the machine electrical systems is an electric motor, converting electrical energy into mechanical. The most widely used in the machine tool industry, especially in universal machines, are alternating current motors - three-phase asynchronous motors.

As is known, the power factor of these electromotors essentially depends on the ratio of the nominal $\left(\mathrm{P}_{\mathrm{n}}\right)$ and real $\left(\mathrm{P}_{\mathrm{r}}\right)$ power on its shaft. At the real power value significantly lower than the nominal value (motor "underload"), the power factor decreases.

Asynchronous motors are widely used in the equipment for the technological processes implementation. In these motors at the power factor on the shaft less than the nominal values the power factor is sharply reduced, approximately from 0.85 at a rated load to 0,2 at idle running, and for example for an asynchronous three-phase motor with a power $\mathrm{P}_{\mathrm{n}}=11 \mathrm{~kW}$, with a load on its shaft of $25 \%$ of its rated power, the power factor is decreased more than twice. It results in the electrical energy consumption significantly greater than required for the technological process implementation, characterized by the cutting power and hence the energy efficiency of this process.

This takes place both at each technological transition and at the whole product processing cycle. This increases the amount of current consumed and, as a result, the amount of power consumed (S) as a whole, and its reactive component (Q) in particular.

This effect is characteristic for technological cutting processes.

In fig. 4, as an example, the multistage roll processing a on a screw-cutting machine (rated motor power - $11 \mathrm{~kW}$ ) technological process real load characteristics are given. 


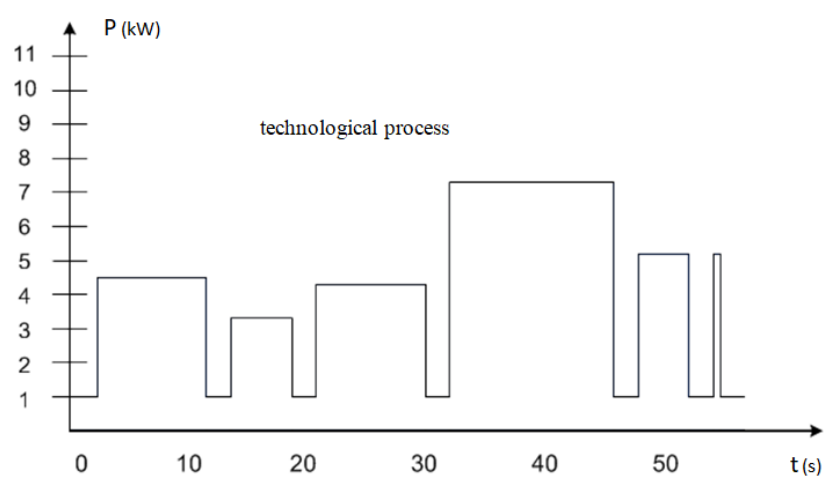

Fig. 4. Multistage roller processing technological process load characteristic (example). Source: own work.

As can be seen in fig. 4, the power of each technological transition and the technological process equivalent power are much lower than the motor rated power.

The elimination of the machine underload consequences may be provided by proper selection of the equipment's power, forced cutting power increase or balancing the power consumption reactive component during the cutting technological process realization. The first method is difficult to implement because of the technological processes wide variety and because all the technological transition capacities vary significantly.

The second method is economically unreasonable, leading to the machine design significant complication. And the third method is implemented through relatively simple means based on phase shift balancing.

The balancing method is of the greatest practical interest for the cutting processes energy efficiency increasing, and therefore for these processes' environmental friendliness improvement.

This method is based on the power factor artificial increase through the phase shift balancing [Hamed et al. 2013].

In this case, at a specific technological cutting process implementation on specific technological equipment, a compensating current is created, with value corresponding to the consumed current reactive component. It is achieved, for example, through the capacity's inclusion parallel to the electromotor phase windings. This method allows to provide adaptation to the actual technological process and equipment where this process is being implemented, the tool state, lubricating and cooling agents, compensation invariance to the other process quality indicators, the method implementation possibility by means of automation, the current consumed reduction, providing additional technological process environmental friendliness by the power circuit wires section reducing. 
The developed automated devices for the power factor increasing, based on the phaseshift balancing method implementation made it possible to reduce energy consumption by 3-5 times at the cutting technological process implementation at the same values of these processes' other quality indicators. The energy approach to the technological cutting processes ecological friendliness analysis allows to solve another important ecological task: the task of quantitative assessment of these processes complex impact on the environment and human at each their specific implementation - to form these processes integral ecological indicator [Egorov et. al. 2016].

Indeed, the cutting power $\mathrm{P}_{\text {cut }}$, brought to the motor shaft, is determined by the machine nominal characteristics and characterizes the technologist's qualification in the field of modern technologies, economics, ecology and other branches of knowledge. To assess the technological process or technological transition integrated environmental quality indicator, implemented with specific equipment in specific conditions, we will pick this value as constant. In this case, the technological cutting processes integral environmental indicator may be determined through these processes' energy efficiency by expression.

$$
I=\frac{P_{\text {cut }}}{S}=\frac{P_{\text {cut }} \cdot \cos \varphi}{P_{\text {cut }}+\sum_{i=1}^{3} \Delta P_{i}}
$$

Indeed, this value characterizes the technological process impact on the environment and human for each specific implementation, as it is determined by the energy losses $\Delta \mathrm{Pi}$ (forming the waste) and the power factor $\cos \varphi$ (determining the excess energy consumption at the machine underload).

From the expression for the technological cutting processes integral ecological index determination it also follows that the reduction of these processes impact on the environment and human (environmental friendliness increase) may be achieved by energy losses reducing at its conversion and transfer to the cutting zone $(\Delta \mathrm{Pi} \rightarrow \mathrm{min})$ and through the increase of the alternating current electrotechnical systems power factor of the machine where the technological process is implemented.

Thus, the technological cutting processes integral environmental indicator increase corresponds to these processes' energy efficiency increase, that means energy consumption reduction at their implementation.

Table. 1. represents the experimental data on the evaluation of the drilling process quality integral ecological index before and after the power factor artificial increase through phase shift balancing method. 
Table 1. Drilling process quality integral ecological index evaluation

\begin{tabular}{|c|l|c|c|c|c|c|}
\hline № & $\begin{array}{c}\text { The capacity of the } \\
\text { technological } \\
\text { process }\left(\mathrm{P}_{\text {cut }}\right), \mathrm{kW}\end{array}$ & $\begin{array}{c}\text { Current } \\
\text { consumption } \\
\text { (I), A }\end{array}$ & $\begin{array}{c}\text { Power } \\
\text { consumption } \\
(\mathrm{S}), \mathrm{kVA}\end{array}$ & $\begin{array}{c}\text { Power } \\
\text { factor } \\
\text { (cos } \varphi)\end{array}$ & $\begin{array}{c}\text { Integral } \\
\text { ecological } \\
\text { indicator }\end{array}$ \\
\hline 1 & 1,35 & 5,5 & 3,7 & 0,36 & 0,38 \\
\hline 2 & $\begin{array}{l}\text { To } \\
\text { compensate } \\
\text { compensate }\end{array}$ & 1,35 & 2,3 & 1,5 & 0,91 & 0,90 \\
\hline
\end{tabular}

Source: own work.

As follows from the table, at the drilling process calculated power brought to the shaft of the machine electromotor $\left(\mathrm{P}_{\mathrm{cut}}=1.35 \mathrm{~kW}\right)$, technological process is implemented at a low power factor $(\cos \varphi=0.36)$ due to the motor underload (the rated motor power is $11 \mathrm{~kW}$ ), it means at large consumed currents $(\mathrm{I}=5.5 \mathrm{~A})$ and at the values of the power intake from the network $(\mathrm{S}=3.7 \mathrm{kVA}$ ), by 2.7 times higher than the power required for this technological process implementation $\left(\mathrm{P}_{\mathrm{cut}}=1.35 \mathrm{~kW}\right)$. At the same time, the integral environmental quality index amounts to much less than one $(\mathrm{I}=0,38)$.

After the power factor artificial increase according to the above described method, the integral ecological indicator value increased to $\mathrm{I}=0.90$, that is by 2.37 times. At the same time, the current consumed during this technological process implementation decreased to the value of $\mathrm{I}=2.3 \mathrm{~A}$, that is by 2.39 times while maintaining all the other technological process quality indicators. The power consumed from the network decreased to $1.5 \mathrm{~kW}$, that is by 2.4 times.

As research has shown, it is the overestimated energy consumption due to the machine "underload" that basically determines the integrated environmental indicator low value of the technological processes implemented with equipment with alternating current electrical systems compared with the energy losses effect on this indicator. For example, in the above case, the energy loss effect on the integral environmental quality index value does not exceed $10 \%$.

The integral ecological indicator of technological cutting processes calculated according to the energy characteristics of these processes allows not only to quantify these processes complex impact on the environment and human at each specific implementation, to formulate the methods for this index increasing, but also to compare various technological processes complex effect on the environment and human.

Table. 2 represents the results of comparison of two different real technological processes according to the integrated ecological indicator - the process of a shaft turning with a diameter of $40 \mathrm{~mm}$ and the process of a hole drilling with a diameter of $80 \mathrm{~mm}$. 
Table 2. Comparison of technological processes according to the integrated environmental indicator

\begin{tabular}{|c|c|c|c|c|}
\hline № & $\begin{array}{c}\text { Technological } \\
\text { process }\end{array}$ & $\begin{array}{c}\text { The capacity of the } \\
\text { technological process } \\
\left(P_{\text {cut }}\right), \mathrm{kW}\end{array}$ & $\begin{array}{c}\text { Power } \\
\text { consumption } \\
(\mathrm{S}), \mathrm{kVA}\end{array}$ & $\begin{array}{c}\text { Integral } \\
\text { ecological } \\
\text { indicator }(\mathrm{I})\end{array}$ \\
\hline 1 & Turning & 1,50 & 6,05 & 0,25 \\
\hline 2 & Drilling & 1,35 & 3,66 & 0,37 \\
\hline
\end{tabular}

Source: own work.

As follows from the table, according to the complex impact on the environment and human, the real drilling process implementation should be preferred, as its integral environmental indicator is higher -0.37 compared to 0.25 .

\section{CONCLISIVE REMARKS}

Thus, the energy approach to the technological cutting processes impact on the environment and human analysis makes it possible to form a unified methodology for these processes the energy efficiency and environmental friendliness assessment at all the diversity of their types and kinds and implementation conditions.

This technique also allows to form the ways of energy efficiency increasing and technological processes environmental friendliness as well as to form a quantitative assessment of their impact on the environment and human - an integrated ecological indicator. This indicator assesses the cutting process environmental friendliness taking into account the actual conditions of these processes' implementation, as well as allows us to compare the technological processes according to their combined effects on the environment and humans - according to their environmental friendliness.

\section{REFERENCES}

Egorov A.V., Kapitanov V.G., Mitrofanov L.E.. Shvartsburg N.A., Ivanova S.A., 2016, Modern digital manufacturing technical support centers IEJME - mathematics education, Vol. 11, No. 7, pp. 2213-2225.

Egorov S.B., Kapitanov A.V., Loktev D.A., 2016, Modern mehods and technological solutions for effective of gear wheels. Materials Science Forum Submitted. Vol. 870, pp. 397-403.

Egorov S.B., Kapitanov A.V., Mitrofanov V.G., Shvartsburg L.E., Natalia A. Ivanova N.A., Ryabov S.A., 2016, Formation of the integral ecological quality index of the 
technological processes in machine building based on their energy efficiency. International Journal of Environmental and Science Education, Vol. 11,No.11, pp.40654978.

Gvozdkova S.I., Shvartsburg L.E., 2017, Analysis of sources and methods for reducing noise by minimizing vibrations of engineering technological processes. Procedia Engineering, Volume 206, pp.958-964.

Hamed, H.H., Aly M.M., El-Arini, Youssef M.T., 2013, Proposed Voltage Ride through Compensators for Improving Power System Performance. International Journal of Energy and Power Engineering, 2(2), pp. 29-36.

Ivanova N.A., Ryabov S.A., Shvartsburg L.E., 2016, The role of information technology in rotor balancing. Russian Engineering Research, Vol. 36, No. 3. pp. 235-238.

Kapitanov A.V., 2016, Characteristics of the Multi - product Manufacturing. Procedia Engineering 150, pp 832-836.

Rodriguez P.E., Shvartsburg L.E., Artemyeva M.Z., 2017, Methodological design and commissioning of an experimental stand for the study of the spread of harmful substances in the air of work areas during the processing of metals in industry. Procedia Engineering, Volume 206, pp. 588-593.

Shvartsburg L., Butrimova E., Yagolnitser O., 2017, Quantitative evaluation of the effectiveness of best available technologies of form-shaping. MATEC Web of Conferences 129, 01027, DOI:10.105, pp.1-4.

Shvartsburg L., Zaborowski T., Cyplik P., 2017, Situation of costs in the logistik process of enterprises. LogForum, 13(4), pp. 495-506.

Shvartsburg L.A., Ivanova N.A., Ryabov S.A., Zaborowski T., 2014, Chemical contaminations in a process of polishing with an implementation of liquid LCTS, Life Science Journal, No 11 (10s), pp. 228-230.

Shvartsburg L.E., Butrimova E.V., Yagolnitser O.V., 2017a, Energy efficiency and ecological safety of shaping technological processes. Procedia Engineering, Volume 206, pp. 10091014.

Yu.V., Golubkov N.V., Ermolaeva L.E., 2016, Shwarzburg Nitrogen-bearing organic components of industrial oils Chemistry and Technology of Fuels and Oils. Vol. 52, No. 1, pp. $1-5$. 